The pyro-soda method for plates, as applied by several devices, is less convenient and takes more time. In any case the removal of air from the medium by lleating to from 90 to $100 \mathrm{C}$. just before planting is advisable.

( $f$ ) The tendency for anaerobes to grow much more easily in symbiosis with aerobic organisms when anaerobiosis is not good makes it necessary to be care$f u l$ in anaerobic methods.

(g) The motility of many anaerobes is an additional reason for care in reducing excessive moisture in the surface of the medium.

The main steps in the method are as follows:

1. An anaerobic culture is made in 1 per cent. glucose bouillon.

2. Successive dilutions are made in physiologic sodium chlorid solution and are shaken thoroughly in corked test tubes containing coarse sand.

3. From each dilution, successive streaks are made on the three or four slants of the modified egg medium of Stitt, made with tryptic broth, with 1 per cent. glucose.

4. They are grown two or three days under good anaerobiosis.

5. Fishing is done from the upper surface of colonies without touching the agar.

\section{CASES SHOWING REMOTE RESULTS OF TESTICLE IMPLANTATION}

\section{G. FRANK LYDSTON, M.D. CHICAGO}

As I exhibited the first of the patients to a number of the members of the American Urological Association, and both patients at the meetings of the Chicago Urological Association in October and November last, there will be no difficulty in verifying the findings given below. As the cases already have been reported in detail, I will give at this time only a brief outline:

\section{REPORT OF CASES}

CASE 1.-A man, aged 30, had completely lost both testicles from infection following trauma. There were moderately marked feminine secondary sex characteristics; excessive and feminine disfribution of fat was especially noticeable. There was complete impotence, with decided mental and physical inefficiency. Double scrotal implantation of entire testicles was performed, Aug. 1, 1915. The material was taken from a boy of 14 , killed by a crushing injury. The testes were removed six hours after death, and kept on ice for thirtythree hours. Local progress of the case was uneventful. The patient returned home at the end of two weeks.

Three weeks later, he engaged successfully in coitus. His mental and physical efficiency rapidly improved and soon became normal. There was a gradual diminution of the flabby, feminine adipose tissue, with an increased masculinity of type. The condition at present, two years and a half after operation, is very satisfactory. The patient is athletic in appearance and indulges freely in athletic sports. He has lost 40 pounds of excess fat. His mental and physical efficiency and sexual power are normal.

The implanted testes still are in situ. The organs are somewhat smaller than those of the average boy of 14 , and quite firm. At the time of operation, a small nodule about the size of a grain of wheat was found at the extremity of the cord on each side. These nodules have grown considerably, and are now about as large as good-sized peas. From present indications, I feel justified in believing that the results of the implantation of testicles in this case will be permanent.
CASE 2.-A boy, at the age of 13 , had suffered severely from a vaccination, probably with a mixed infection. Shortly after the vaccination, which, he stated, made him very ill, he developed orchitis in one testicle, probably from an infected embolus. Following the orchitis the testiclc atrophied. Several weeks later, the opposite testicle became similarly involved and speedily atrophied. Coincidentally, the penis became distinctly smaller. Some months later, the patient was examined by several surgeons, who diagnosed retained testis on the left side and suggested operation. The patient subsequently, when 17 years of age, was referred to me. $\mathrm{He}$ was tall and healthy looking, with distinctly feminine secondary sexual characteristics. The pelvis, mons veneris and manmary glands were suggestive of a girl just entering on puberty. No beard was in evidence, and the complexion was distinctly of the "milk and blood" feminine type. There was a bare suggestion of hair on the pubis. The left testicle was represented by a small, hardly perceptible nodule about as large as a small pea just below the external inguinal ring. The right testis was soft, outlined with difficulty, and about the size and shape of a small lima bean. The penis was no larger than that of a well developed child of 5 or 6 years of age. The voice was that of the ustual boy of 17 . Psychically, the boy fortunately was a normal, manly fellow, although there were no signs of virility.

After about six months' treatment with faradism with some slight improvement, I suggested an implantaticn. Other advice was sought, and several surgeons-one supposedly an authority-suggested operation for retained testis, despite the feminine sexual characteristics, and local conditions that plainly showed the absurdity of such an operation. The patient passed from my observation and did not return until two years later, when I found that an operation had been performed on the left side, with the inevitable result that the remnant of testicle on that side had completely disappeared.

At the second examination, the condition in general was the same as it had been two years before, save that the secondary feminine sexual characteristics were more pronounced. There still had been no manifestations of virility. The pelvis was distinctly feminine, and the mons veneris was covered with a well pronounced cushion of fat and very sparsely supplied with small hairs, the arrangement of which was suggestive of that of a young girl approaching puberty. The beard still was lacking. Implantation of the testes again was suggested and consented to.

The operation, scrotal implantation, was performed, Oct. 27,1916 . The material used was taken from a healthy boy, aged 15, twenty-four hours after death from carbon monoxid poisoning. The glands were refrigerated thirty-two hours. The epididymides were not removed, and the testes were not decorticated. There was very little reaction and practically no elevation of temperature following the operation, but the patient was kept in bed for ten days.

Sixteen months after the implantation, the implanted testes still are well defined, the right gland being much larger than the left, and both being as large as those of the average lad of from 12 to 14 . The consistency of both glands is softer and more nearly approximates the normal than have any other thus far implanted. The patient has gained weight and strength and is virile, as demonstrated by moderately frequent erections and the fact that he has cohabited thrice in succession on numerous occasions, with orgasm and emission. Penile development has greatly increased, and the pubic and scrotal hair also has increased and assumed a more masculine type. The lines of the patient's body have changed appreciably and become more masculine in conformation. the cushion of fat on the mons veneris, especially, being reduced in size. The patient's own atrophied right testicle has increased in size and firmness, and the epididymis-which could not be discerned at the time of the implantation-now can be plainly outlined. The voice is distinctly more masculine ; the beard is heavier, and a growth of hair has appeared on the forearms. As in Case 1, I believe that the results in this case are likely to be permanent. It must be remembered that these two cases comprise four distinct and separate successful testicle implantations. 


\section{COMMENT}

I not only feel that my published impressions of the value of the sex gland implantation - notably in the matter of increasing physical efficiency, and especially physiosexual efficiency - have been confirmed by further experience, but I also am convinced that, when technic and material are right and the recipient is properly selected, continuity of hormone production by the implanted gland for at least a prolonged period is certain. That permanently beneficial physiologic and therapeutic results are equally certain seems probable. Thus far I have observed no case in which the implanted tissue has completely or even practically clisappeared, prior to from twelve to eighteen months. In brief, I am convinced that my method of sex gland implantation long since has been taken from the purely experimental field, and that it now stands on firm ground as a valuable therapeutic resource.

25 East Washington Street.

\section{TOXICITY OF THE AMERICAN-MADE ARSPHENAMIN (SALVARSAN)}

\section{REPORT OF CASES}

\section{JAMES C. SARGENT, M.D. MILWAUKEE}

At the outbreak of the world war, the original (icrman-made salvarsan practically ceased being marketed in America as well as in France and England. The demand for the preparation had already assumed massive proportions. The natural result of this unsupplied demand was the manufacture of similar, if not identical, products by various concerns. I)iarsenol, arsenobenzol, arsenobenzol "Billon" and other preparations were soon marketed as its substitute. Recently a preparation has appeared under the trade name of "Salvarsan," (arsphenamin) ostensibly manufactured in this country under the direction of the Farbwerke-Hoechst Company and by the process cmployed in the manufacture of the old German-made salvarsan.

Taking advantage of the large syphilitic clinic at the Marquette University School of Medicine, I have been attempting to arrive at some conclusions as to the relative therapeutic value and toxicity of these different preparations. A paper outlining this work is in the writing.

Recently the dispensary has been able to obtain some of the new arsphenamin now being made in New York by representatives of the Farbwerke-Hoechst Company of Germany. Having this new shipment at hand, I decided to give it a trial on five patients who had reported that day for an arsphenamin treatment. Three ampules, each containing $0.6 \mathrm{gm}$. of arsphenamin, were inspected and found not to be cracked. The contents of each was of the characteristic pale yellow color. The total of these ampules was dissolved in 225 c.c. of sterile water which had been distilled less than two hours before. After the arsphenamin was entirely dissolved, the solution was alkalized by the addition of a sufficient quantity of 15 per cent. sodium hydroxid to form and redissolve the precipitate. It might be said that this technic, together with that of the injection of the solution, was identical with that used in the administration of some 200 doses of salvarsan given in the past six months.

\section{REPORT OF CASES}

CASE 1.-A young woman, with a recently suppressed secondary syphilis, had received five salvarsan treatments at intervals of two and three weeks without notable reactions. She was given 50 c.c. of the prepared solution $(0.4 \mathrm{gm}$. of salvarsan) in one of the arm veins. As she was leaving the building she became cyanotic and fainted. She soon regained consciousness and began vomiting severely. When I saw her about fifteen minutes later she was very pale, had a fast, thready pulse, was still vomiting and was in a violent chill in spite of blankets. After an hour's rest she was sent home in an ambulance. She subsequently reported that she continued nauseated and chilled for about twelve hours.

CASE 2.-A young man, suffering from an active hereditary syphilis, had received one injection of salvarsan the week before. No reaction followed. He was given 50 c.c. of the prepared solution $(0.4 \mathrm{gm}$. of salvarsan). He walked to an adjoining room and was forced to sit down because of a sudden dizziness. He became cyanotic, was nauseated, and hungered for air. His pulse rose above a hundred and was of little volume. After resting an hour, he was allowed to return home. He subsequently reported that he had a severe headache, was nauseated, and remained very chilly for four hours despite going to bed.

CASE 3.-A small colored boy, with an active hereditary syphilis, had received one salvarsan treatment the week before without reaction. He was given 25 c.c. of the solution ( $0.2 \mathrm{gm}$. of salvarsan) and left the dispensary. His guardian subsequently reported that he appeared to have suffered no réaction.

As I was about to give the fourth injection, I was informed of the condition of Patients 1 and 2. Becoming alarmed, I tested a part of the remaining solution with dilute hydrochloric acid and found that the precipitate reformed on acidulation. Being satisfied that the solution was properly alkalized, I diluted it with freshly distilled and sterilized water so that 50 c.c. contained a fraction less than $0.3 \mathrm{gm}$. of salvarsan.

CASE 4.-A middle aged man, suffering a late syphiloderm, had received an injection of salvarsan the week before without reaction. He was given 50 c.c. of the remaining solution ( $0.3 \mathrm{gm}$. of salvarsan). Arising from the table, he complained of dizziness and faintness; but after resting a half hour he decided to return home. He subsequently stated that he suffered only a slight headache for the following twelve hours.

CASE 5.-A young man in the late primary stage of syphilis had received no previous treatment. The needle was introduced into the vein, and the solution allowed to run. After 30 c.c. ( $0.18 \mathrm{gm}$. salvarsan) had been injected, he began coughing, became cyanotic, and complained of air hunger. The injection was stopped. The pulse became rapid and thin. In spite of blankets he continued in a violent chill for thirty minutes. After an hour his color returned and he was allowed to go home. He subsequently reported that he remained chilly, nauseated and with a bad headache for the following four hours. This patient had had a preliminary cathartic.

\section{COMMENT}

Having been convinced that these five cases alone were sufficient to give a very definite idea of the toxicity of the new American-made salvarsan (arsphenamin), I have abandoned its use. Realizing the wide reputation previously enjoyed by the old Germanmade product and the stimulus which that reputation is certain to give to the sale of the new American-made salvarsan, I have been constrained to make an early report of these cases, hoping to save others from my uncomfortable experience. 